\title{
Ciclosporiasis: distribución, prevalencia y control
}

\author{
Leonor Chacín Bonilla y Jose Ramon Vielma ${ }^{2,3}$ \\ ${ }^{1}$ Instituto de Investigaciones Clínicas “Dr. Américo Negrette”, Facultad de Medicina. Universidad \\ del Zulia. Maracaibo, Venezuela. \\ ${ }^{2}$ Laboratorio de Fisiología de Parásitos, Centro de Biofísica y Bioquímica. Instituto Venezolano de \\ Investigaciones Científicas. Altos de Pipe, Venezuela. \\ ${ }^{3}$ Laboratorio de Análisis Químico. Universidad Nacional Experimental Sur del Lago "Jesús María \\ Semprum”. Santa Bárbara del Zulia, Venezuela.
}

Palabras clave: ciclosporiasis; Cyclospora cayetanensis; epidemiología; control.

Resumen. Cyclospora cayetanensis es un protista emergente que causa enfermedad diarreica. El parásito se reporta en todo el mundo. Los seres humanos son los únicos hospedadores conocidos. Cyclospora es una causa importante de morbilidad en niños y pacientes con SIDA y de epidemias transmitidas por los alimentos. La globalización del suministro de alimentos y el aumento de los viajes internacionales han contribuido a la propagación del parásito a zonas no endémicas. La mayoría de los casos se han relacionado con viajeros o brotes transmitidos por los alimentos. Cyclospora ha sido aislada de frutas, verduras, mariscos, agua potable, piscinas, lagos, ríos, aguas residuales y suelos. Los ooquistes son resistentes a las condiciones ambientales, los insecticidas y los desinfectantes. Actualmente no existen técnicas para el análisis de ADN y la discriminación por genotipo. La falta de un modelo animal y los escasos datos de las secuencias de ADN han obstaculizado el desarrollo de métodos para su detección. Recientemente se han obtenido los genomas completos de mitocondrias y apicoplastos de $C$. cayetanensis que podrían facilitar la tipificación genética. Las medidas de prevención y control incluyen la buena higiene personal, el saneamiento ambiental eficiente y el mejoramiento de la calidad del agua. La cuantificación del riesgo y el control de Cyclospora en el medio ambiente se complican por la mínima dosis infecciosa, los ooquistes resistentes y los largos períodos pre-patentes y de esporulación. Esta revisión resume el conocimiento actual del parásito centrándose en la distribución, la prevalencia y las estrategias de control de la infección.

Autor de Correspondencia: Leonor Chacín-Bonilla. Instituto de Investigaciones Clínicas “Dr. Américo Negrette”, Facultad de Medicina. Universidad del Zulia. Maracaibo, Venezuela. Correo electrónico: leonorbonilla42@yahoo.com 


\title{
Cyclosporiasis: distribution, prevalence and control
}

Invest Clin 2018; 59(1): 67 - 93

Keywords: cyclosporiasis; Cyclospora cayetanensis; epidemiology; control.

\begin{abstract}
Cyclospora cayetanensis is recognized as an emerging protist that causes diarrheal illness. The parasite is endemic in tropical areas but reported worldwide. Humans are the only hosts known. Cyclospora is responsible for significant morbidity in children and AIDS patients and is an important cause of foodborne outbreaks. Globalization of the food supply and increased world travel have contributed to the spread of the parasite to non-endemic areas. Most of the cases have been linked with travelers or foodborne outbreaks. Berries and leafy green vegetables have been implicated as food sources. Cyclospora has been isolated from fruits, vegetables, shellfish, drinking water, swimming pools, lakes, rivers, wastewater, sewage water, and soil. The oocysts are highly resistant to environmental conditions, pesticides, and disinfectants. Techniques for fingerprinting analysis and genotype discrimination are not available. The lack of an animal model and limited DNA sequence data have hampered efforts to develop detection methods. The complete apicoplast and mitochondrial genomes of C. cayetanensis were recently obtained which could facilitate the development of genotyping tools. Prevention and control measures include improvement of personal hygiene, efficient sanitation, and improved water quality management. Food safety training worldwide is necessary. Quantifying risk and controlling Cyclospora in the environment are complicated by the minimum infectious dose, the highly resistant oocysts, and the long sporulation and prepatent periods. This review summarizes the current status of knowledge of the parasite focusing on distribution, prevalence, and control strategies of infection.
\end{abstract}

Recibido: 12-06-2017 Aceptado: 10-11-2017

\section{INTRODUCCIÓN}

Cyclospora cayetanensis es un coccidio que se transmite entre humanos; hasta el presente, no se ha demostrado que existan animales reservorios del parásito. La infección tiene una distribución global; se ha observado en países en vías de desarrollo e industrializados. La transmisión puede ocurrir a través de alimentos, aguas y suelos contaminados. La ciclosporiasis produce manifestaciones gastrointestinales autolimitadas, especialmente diarrea, aunque también puede ser asintomática o crónica en individuos inmunosuprimidos. En áreas endémicas, los más susceptibles a la enfermedad son los niños pequeños y los individuos inmunocomprometidos y en países desarrollados, todos son propensos a sufrirla (1). 
En áreas industrializadas, el riesgo a adquirir la infección ha aumentado con la globalización del suministro de alimentos, con la apertura de nuevos mercados para frutas y vegetales frescos de áreas endémicas y el incremento de los viajes internacionales y del movimiento migratorio (1).

En áreas endémicas, el mejoramiento del saneamiento ambiental y de la higiene personal puede reducir la contaminación del ambiente y la exposición a heces humanas. Para prevenir la contaminación de las frutas y los vegetales en las fábricas, se deben establecer normas para evitar la contaminación durante su procesamiento y producción $(2,3)$. En los países industrializados, la vigilancia de la ciclosporiasis y otras enfermedades transmitidas por alimentos se ha convertido en un componente fundamental de los sistemas de seguridad para los alimentos (4). El hacer cumplir las leyes del comercio internacional de alimentos y la implementación de métodos que usen los acuerdos de puntos de control críticos pueden ayudar en el control de la infección (5).

\section{DISTRIBUCIÓN}

\section{Distribución geográfica}

La infección por $C$. cayetanensis está ampliamente distribuida en el mundo. Se ha reportado en humanos en forma endémica o esporádica en países en vías de desarrollo $\mathrm{y}$ principalmente en forma epidémica en naciones desarrolladas (1). C. cayetanensis se ha identificado también en diferentes matrices ambientales en áreas en desarrollo e industrializadas (6).

Áreas en vías de desarrollo. La ciclosporiasis se ha documentado como endémica en algunos países (1). Se han identificado casos esporádicos de la infección en los residentes en Argentina (7), Kuwait (8), Bangladesh (9), Nueva Guinea (10) y Sudáfrica (11) o en visitantes extranjeros en Puerto Rico (12), República Dominicana (13-15), Costa Rica (16), Bolivia (17), Bulgaria (18), Sri Lanka, Gabón (19), Líbano (20), Cambodia, las Islas Salomón (21), Pakistán (22), Java, Bali (23) y Madagascar (24). Aun cuando se desconoce la prevalencia de la infección en estas naciones, estos hallazgos reflejan su endemicidad en estas áreas. De hecho, en República Dominicana, donde sólo se habían publicado infecciones en viajeros, un estudio consiguió una prevalencia de 2,3\% (9/398) (25). En los países donde la infección es endémica, se han reportado tasas de infección de 0 a 41,6\% (Tabla I). Las variaciones en la prevalencia pueden estar influenciadas por el diseño del estudio, el área geográfica, la edad y el estado inmunológico de la población estudiada, la estacionalidad del parásito, los métodos de diagnóstico utilizados y la experiencia del microscopista.

En los pacientes inmunocomprometidos, principalmente en aquellos positivos para el VIH/SIDA y con diarrea, los porcentajes de infección por Cyclospora han oscilado entre 0 a 36\% (1, 32). En Venezuela, Colombia, Arabia Saudita, Malasia, Tanzania y Camerún, se han observado tasas de infección de 6,8-9,8, 2,6, 5,9, $4,9,1,2$, y $3,6 \%$, respectivamente $(32,57-62)$.

En el mundo en desarrollo, también se han observado epidemias de ciclosporiasis en residentes locales y extranjeros o visitantes $(63,64,66)$ (Tabla II). La explicación de estos brotes en adultos residentes es que la inmunidad adquirida en estas áreas no es duradera sino que se desvanece con el tiempo (86) o que la distribución geográfica, prevalencia $y$ propagación del parásito en una región puede variar de un lugar a otro dejando algunas poblaciones desprotegidas, sobre todo las de la clase social superior (87). Los brotes escasos de ciclosporiasis en regiones endémicas podrían deberse al uso indiscriminado de antibióticos eficaces contra el parásito y la falta de capacidad

Vol. 59(1): 67 - 93, 2018 
TABLA I

PREVALENCIA DE CYCLOSPORA EN INDIVIDUOS INMUNOCOMPETENTES DE PAÍSES EN DESARROLLO

\begin{tabular}{|c|c|c|c|}
\hline País & Población & $\begin{array}{l}\text { Infectados } \\
\%(\mathrm{n} / \mathrm{n} \text { total })\end{array}$ & Referencia \\
\hline México & Niños & $3,3(9 / 272)$ & $(26)$ \\
\hline & Niños & $0,6(60 / 8.877)$ & (27) \\
\hline Guatemala & Todas las edades & $2,3(126 / 5.552)$ & (28) \\
\hline & Granjeros $^{\mathrm{a}}$ & $3,3(6 / 182)$ & (28) \\
\hline Honduras & Todas las edades & $2,0(96 / 4.698)$ & (29) \\
\hline Cuba & 0-7 años & $4,4(5 / 113)$ & (30) \\
\hline Haití & Todas las edades & $6,0(24 / 402)$ & (31) \\
\hline Rep. Dominicana & Todas las edades & $2,3(9 / 398)$ & (25) \\
\hline \multirow[t]{4}{*}{ Venezuela } & Niños & $5,3(7 / 132)$ & (32) \\
\hline & Todas las edades & $6,1(13 / 212)$ & (33) \\
\hline & Todas las edades & $8,3(43 / 515)$ & (34) \\
\hline & Todas las edades & $24,2(38 / 157)$ & (35) \\
\hline Brasil & Todas las edades & $10,8(9 / 83)$ & (36) \\
\hline \multirow[t]{3}{*}{ Perú } & $0-2,6$ años & $10,9(41 / 377)$ & (37) \\
\hline & Niños & $1,1(63 / 5.836)$ & (38) \\
\hline & Todas las edades & $41,6(121 / 291)$ & (39) \\
\hline \multirow[t]{2}{*}{ Turquía } & Todas las edades & $0,4(2 / 554)$ & (40) \\
\hline & Todas las edades & $5,7(129 / 2.281)$ & (41) \\
\hline Marruecos & Escolares & $3,3(22 / 673)$ & (42) \\
\hline Egipto & Todas las edades & $9,2(12 / 130)$ & (43) \\
\hline Jordania & Todas las edades & $6,0(12 / 200)$ & (44) \\
\hline Arabia Saudita & $<5$ años & $11,1(7 / 63)$ & (45) \\
\hline India & Todas las edades & $10,6(33 / 310)$ & (46) \\
\hline \multirow[t]{2}{*}{ China } & Todas las edades & $5,6(10 / 178)$ & (47) \\
\hline & Niños & $0(0 / 252)^{b}$ & (48) \\
\hline \multirow[t]{3}{*}{ Nepal } & Todas las edades & $9,2(128 / 1.397)$ & (49) \\
\hline & Escolares & $1,6(23 / 1.392)$ & (50) \\
\hline & Escolares & $3,9(20 / 507)$ & (51) \\
\hline Bangladesh & 2-5 años & $0(0 / 289)$ & (52) \\
\hline Laos RDP & Todas las edades & $0,1(1 / 686)$ & (49) \\
\hline Vietnam & Todas las edades & $1,0(14 / 1.425)$ & (53) \\
\hline Tailandia & Todas las edades & $0,5(12 / 2.540)^{\mathrm{b}}$ & (54) \\
\hline Indonesia & Escolares & $0,6(2 / 348)$ & (55) \\
\hline Nigeria & Todas las edades & $1,0(11 / 1.109)$ & (56) \\
\hline
\end{tabular}

${ }^{\mathrm{a}}$ Cultivadores de frambuesas; ${ }^{b}$ Métodos PCR. 
Ciclosporiasis: distribución, prevalencia y control.

71

TABLA II

EPIDEMIAS DE CICLOSPORIASIS EN EL MUNDO

\begin{tabular}{|c|c|c|c|c|c|}
\hline Fecha & País: Localización & No. de casos $^{\mathrm{a}}$ & Vehículo & Origen & erencia \\
\hline$\overline{1989 \text { Jun }}$ & Nepal: Pokhara & 14 & Agua de grifo, río & Nepal & $(63)$ \\
\hline 1989 Jun-Nov & Nepal: Katmandú & 535 & $\mathrm{ND}^{\mathrm{b}}$ & ND & (64) \\
\hline $1990 \mathrm{Jul}$ & USA: Illinois & 21 & Agua de grifo & USA & $(65)$ \\
\hline 1992 & Nepal: Katmandú & 964 & Agua potable & Nepal & (66) \\
\hline 1995 May & USA: Florida & 38 & Frambuesas $^{c}$ & Guatemala $^{c}$ & (67) \\
\hline 1995 May-Jun & USA: Nueva York & 32 & Alimentos & ND & (68) \\
\hline 1996 May & USA: Boston, MA & 57 & Postre de bayas & $\begin{array}{c}\text { USA, Chile, } \\
\text { Guatemala }\end{array}$ & (69) \\
\hline \multirow{2}{*}{$\begin{array}{l}1996 \text { May-Jun } \\
1997 \text { Mar- May }\end{array}$} & USA, Canadád & 1.465 & Frambuesas & Guatemala & (70) \\
\hline & $\begin{array}{l}\text { USA crucero: } \\
\text { salida de Florida }\end{array}$ & 220 & Frambuesas & Guatemala & (71) \\
\hline 1997 Abr-May & USA, Canadád $^{d}$ & 1.012 & Frambuesas & Guatemala & (72) \\
\hline \multirow[t]{2}{*}{1997 Jul } & $\begin{array}{l}\text { USA: Washington DC } \\
\text { USA: Virginia, }\end{array}$ & 341 & Albahaca & Múltiple & (68) \\
\hline & Washington, DC & 48 & Albahaca & ND & (73) \\
\hline 1997 Sep & USA: Virginia & 21 & Frutas & ND & (68) \\
\hline 1997 Dic & USA: Florida & 12 & Ensalada de hojas & Perú & (68) \\
\hline 1998 May & USA: Georgia & 17 & Ensalada de frutas & ND & (68) \\
\hline 1998 May-Jun & Canadá: Ontario & 315 & Frambuesas & Guatemala & (74) \\
\hline 1999 May & Canadá: Ontario & 104 & Postre de bayas & ND & $(68)$ \\
\hline 1999 May & USA: Florida & 94 & Frutas & ND & (68) \\
\hline 1999 Jul & USA: Missouri & 64 & Albahaca & USA, México & $(75)$ \\
\hline 2000 Jun & USA: Pensilvania & 54 & Torta de frambuesa & Guatemala & (76) \\
\hline 2000 Dic & Alemania & 34 & Ensaladas, hierbas & $\begin{array}{c}\text { Francia, Italia, } \\
\text { Alemania }\end{array}$ & $(77)$ \\
\hline $2001 \mathrm{Abr}$ & México: Monterrey & 97 & Berro & ND & (78) \\
\hline 2001 May & Canadá: $\mathrm{CB}^{\mathrm{e}}$ & 17 & Albahaca & USA & (79) \\
\hline 2001 Sep & Indonesia: Bangkok & 14 & ND & ND & $(80)$ \\
\hline $2002 \mathrm{Abr}$ & Colombia: Medellín & 31 & Ensaladas, jugos & ND & $(81)$ \\
\hline 2003 May & España: Madrid & $11^{\mathrm{f}}$ & Jugo de frambuesas & Guatemala & $(82)$ \\
\hline $2003 \mathrm{Jul}$ & Canadá: CB & 11 & Cilantro $^{c}$ & ND & $(83)$ \\
\hline 2004 & Canadá: CB & 17 & Mango, albahaca ${ }^{c}$ & ND & (83) \\
\hline $2004 \mathrm{Feb}$ & USA: Texas, Illinois & 95 & ND & ND & (18) \\
\hline 2004 May-Jun & Canadá: CB & 8 & Cilantro $^{c}$ & ND & (84) \\
\hline 2004 Jun-Jul & USA: Pensilvania & 96 & Guisantes & Guatemala & $(85)$ \\
\hline 2004 Nov & Perú: Lima & 127 & ND & ND & (86) \\
\hline 2005 Mar & Perú: Lima & 37 & ND & ND & (87) \\
\hline $2005 \mathrm{Abr}$ & Canadá: Ontario & 44 & Albahaca $^{c}$ & ND & $(83)$ \\
\hline
\end{tabular}

Vol. 59(1): 67 - 93, 2018 


\section{TABLA II \\ EPIDEMIAS DE CICLOSPORIASIS EN EL MUNDO (CONTINUACION)}

\begin{tabular}{|c|c|c|c|c|c|}
\hline$\overline{\text { Fecha }}$ & País: Localización & No. de $\operatorname{casos}^{\mathrm{a}}$ & Vehículo & Origen & Referencia \\
\hline $2005 \mathrm{Abr}$ & USA: Florida & 592 & Albahaca & ND & $(88)$ \\
\hline $2005 \mathrm{Jul}$ & Canadá: Quebec & 200 & Albahaca & México & (89) \\
\hline 2005 Sep & Turquía: Esmirna & 19 & Agua potable & ND & $(40)$ \\
\hline 2006 Jun-Jul & Canadá: CB & 28 & Albahaca, ajo & ND & (83) \\
\hline 2007 May-Ago & Canadá: CB & 29 & Albahaca & México & $(90)$ \\
\hline 2007 Jul-Ago & Turquía: Estambul & 286 & ND & ND & (91) \\
\hline $2009 \mathrm{Abr}$ & Crucero: varios países & 160 & ND & ND & (92) \\
\hline 2009 May-Jun & Suecia: Estocolmo & 18 & Guisantes & Guatemala & (93) \\
\hline 2010 May-Jun & $\begin{array}{l}\text { Australia crucero: } \\
\text { salida de Fremantle }\end{array}$ & $266^{\mathrm{g}}$ & Lechuga $^{c}$ & Malasiac $^{c}$ & (94) \\
\hline 2013 Jun-Ago & $\begin{array}{l}\text { USA }^{\mathrm{d}}: \text { Texas } \\
\text { Iowa, Nebraska }\end{array}$ & $\begin{array}{l}270 \\
227\end{array}$ & $\begin{array}{l}\text { Cilantro } \\
\text { Lechuga }\end{array}$ & $\begin{array}{l}\text { México } \\
\text { México }\end{array}$ & $\begin{array}{l}(95) \\
(96)\end{array}$ \\
\hline 2013 Nov & Polonia & $3^{f}$ & Agua potable & Indonesia & (97) \\
\hline 2015 May-Ago & Canadád & 97 & ND & ND & $(98)$ \\
\hline 2015 Jun-Sep & Reino Unido $^{\mathrm{d}}$ & 79 & ND & México & (99) \\
\hline 2014 Jun-Ago & $\mathrm{USA}^{\mathrm{d}}$ & 304 & Cilantro & México & $(100)$ \\
\hline 2015 May-Ago & $\mathrm{USA}^{\mathrm{d}}$ & 546 & Cilantro & ND & (101) \\
\hline
\end{tabular}

${ }^{a}$ Casos clínicamente definidos y confirmados en laboratorio; ${ }^{b}$ No determinado; ${ }^{\circ}$ Sospechoso;

${ }^{d}$ Epidemias multi-estatales; ${ }^{\mathrm{e}}$ Columbia Británica; ${ }^{\mathrm{f}}$ Viajeros; ${ }^{\mathrm{g}} 34$ y 232 casos en dos viajes consecutivos.

de diagnóstico (86).

Países industrializados. En las naciones desarrolladas, los casos de ciclosporiasis están vinculados sobre todo a viajes internacionales $\mathrm{y}$ al consumo de frutas $\mathrm{y}$ vegetales crudos importados contaminados, generalmente de regiones donde la infección es endémica. El parásito es una causa frecuente de diarrea del viajero. Los primeros casos documentados en USA se produjeron a mediados de la década de 1980 en viajeros que regresaban de Haití y México (102). Entre 1997 y 2008, 33,5\% de los casos de infección confirmados en laboratorio en USA y $71 \%$ de los casos en 2006 en Canadá, eran viajeros $(103,104)$. El coccidio fue documentado como un patógeno importante en humanos a mediados de los 90 cuando fue

reconocido como el agente causal de epidemias de enfermedad diarreica multi-estatales en USA y Canadá, asociados principalmente con alimentos frescos como bayas y verduras importadas de México y Centroamérica (2, 68, $70,72,105,106)$. Desde 1990, la mayoría de las epidemias registradas en USA y Canadá se han asociado con alimentos y casi todos los casos han estado relacionados con frambuesas guatemaltecas. Estos brotes han ocurrido durante la primavera y principios de verano, que son temporadas cálidas y lluviosas $(68,107)$. El brote que le dio importancia a la infección en América del Norte y estableció el vínculo con la transmisión a través de alimentos se produjo en la primavera de 1996 y fue diseminado por frambuesas frescas importadas de Guatemala. 
Un total de 1.465 casos fueron reportados por 20 estados y el Distrito de Columbia en USA y dos provincias canadienses (70). En la década de 1990, por lo menos, 19 epidemias de ciclosporiasis se documentaron en todo el mundo, de las cuales 16 fueron registradas regularmente en América del Norte incluyendo brotes de alto perfil que afectaron varios estados en USA y varias provincias de Canadá. Desde el año 2000, al menos 31 epidemias han sido reportadas en todo el mundo, 17 en América del Norte (Tabla II). Los brotes multiestatales de 2013 en USA afectaron 25 estados (principalmente Texas, Iowa y Nebraska) con 631 casos confirmados de la enfermedad. Estos brotes contribuyeron al número anual de casos de ciclosporiasis más grande reportado en USA desde 1997 (95). Las epidemias multi-estatales de 2014 y 2015 en este país involucraron 304 y 546 casos confirmados en 19 y 31 estados, respectivamente; la mayoría de los casos fueron residentes de Texas $(100,101)$. El brote de 2015 en Canadá afectó las provincias de Ontario y Quebec (98). La mayoría de las epidemias de ciclosporiasis se ha notificado en América del Norte, probablemente debido a mejores métodos de detección y vigilancia de las enfermedades que han contribuido en el seguimiento de los brotes $(6,86)$.

En América del Norte, se han identificado epidemias de ciclosporiasis transmitidas por el agua $(2,65,108,109)$. La diseminación de la infección por exposición a aguas de consumo, recreacional, o residuales se ha observado con menor frecuencia $(2,110-112)$. A diferencia de USA y Canadá, la mayoría de los casos de ciclosporiasis en Europa y Australia se han vinculado con viajes internacionales a zonas endémicas. La infección se ha reportado en España, Francia, Bélgica, Italia, Alemania, Grecia, Reino Unido, Irlanda, Suecia, Suiza, Holanda, los Países Bajos, Nueva Zelanda y Australia $(17,18,24,82,113,114)$. También se han notificado brotes de ciclosporiasis en viajeros de España (82), Polonia (97) y el Reino Unido (99) (Tabla II).

En USA, se han observado casos de la infección sin historia de consumo de alimentos importados de áreas endémicas ni viajes internacionales (110-112). La tasa de infección endémica de $C y c l o s p o r a$ en la población general de América del Norte y Reino Unido fue menos del $0,5 \%$ entre 1992 y 1995 durante los períodos no epidémicos $(68,115)$. De un total de 370 casos confirmados durante 1997-2009 mediante la Red de Vigilancia Activa de Enfermedades Transmitidas por los Alimentos en USA, $70,3 \%$ de ellos se concentraron en Georgia y Connecticut. Durante el período 2004-2009, $37,8 \%(70 / 185)$ de los casos fueron clasificados como adquiridos nacionalmente (116). En USA, se considera que la ciclosporiasis no es endémica aunque se ha pensado en la posibilidad de focos con baja endemicidad $(68,117)$. En Alemania, las fuentes de transmisión por alimentos de una epidemia se vincularon a lechugas y hierbas de Alemania, Francia e Italia; la contaminación de los alimentos pudo haber ocurrido por agricultores sin acceso a facilidades sanitarias adecuadas (77)

\section{Distribución estacional}

Se ha descrito una marcada estacionalidad de la prevalencia de la infección por Cyclospora, dependiendo del clima, en diversas regiones endémicas. Sin embargo, no es uniforme; lo cual no es fácil de explicar (68).

La tendencia estacional que se describe a menudo coincide con períodos cálidos de máxima precipitación según lo observado en Guatemala (28), Honduras (29), México (27), Jordania (44), Nepal (49, 51, 66, 118, 119), Indonesia (55) y China (120). En contraste, la infección ha sido más frecuente durante los meses más secos y calientes del año en la ausencia de lluvias en Lima, Perú $(38,121)$ y 
Turquía (122) y en el tiempo más fresco en Haití, donde las fluctuaciones de temperatura parecen ser el moderador de la estacionalidad (123). La variación estacional de $C$. cayetanensis sugiere que los factores ambientales son importantes en su ciclo de vida y que es probable que sea influenciado por varios de ellos como la precipitación, la temperatura y la humedad (6, 123).

\section{Distribución por edad y sexo.}

En áreas endémicas, se ha observado que la ciclosporiasis es común en los niños. A menudo son asintomáticos o tienen síntomas relativamente leves $(33,34,38,123,124)$. Se ha notado un alto porcentaje de portadores asintomáticos $(68,2-98,7 \%$, promedio $87,1 \%)$ en comunidades $(1,51)$; en algunos estudios, hasta el $100 \%$ de los niños infectados fueron asintomáticos (54), sugiriendo el desarrollo de protección inmunológica. Así que en áreas endémicas, el papel patógeno de $C$. cayetanensis no es consistente. Esta situación en la población en general es bastante diferente a la que se ha observado en los niños que acuden a centros de salud en los cuales se ha reconocido una fuerte asociación del parásito con diarrea (30, $45,55,125,126)$. Este hallazgo sugiere que la ciclosporiasis es común en zonas empobrecidas donde la limpieza de los alimentos, el tratamiento del agua y el saneamiento ambiental son deficientes o inexistentes y que la exposición temprana y persistente puede estar asociada con inmunidad a la enfermedad e infección asintomática $(38,121,124)$. De hecho, después de un episodio inicial de ciclosporiasis, la probabilidad de diarrea y duración de los síntomas disminuye significativamente con cada infección subsecuente (121).

El mayor riesgo de ciclosporiasis sintomática ocurre en los primeros cinco años de vida $(32,38$, $118,121,127)$. En niños menores de 18 meses, la infección se detectó en Nepal $(119,128)$, fue infrecuente en Guatemala (28) y Venezuela (32) y asintomática en Perú (37). Se desconoce si esto es debido a los anticuerpos maternos o por exposición ambiental limitada en este grupo de edad (118).

Los estudios comunitarios de distribución de la infección por edad son escasos. En un estudio durante 2 años en Perú, la prevalencia de $C$. cayetanensis fue más alta en los niños de 2 a 4 años y no se observó en personas mayores de 18 años de edad (38). En otro estudio de la misma región, la infección no fue detectada en personas mayores de 11 años (127). En Guatemala (28), Honduras (29), Haití (31), Cuba (30), Venezuela (34), Nepal $(49,50)$, Turquía (122) y Tailandia (54) la infección fue más frecuente en niños escolares $<15$ años de edad. En Henan, China, los niños de 7-17 años de edad tenían la tasa de infección más alta (120). Las causas de este patrón de distribución por edad no están claras, pero pueden estar relacionadas con los modos predominantes de la exposición. Cyclospora se transmite generalmente por la exposición a fuentes ambientales contaminadas de las cuales los niños pequeños están relativamente protegidos (121). En relación al sexo, no se han notado diferencias significativas. En Haití y Venezuela la proporción de riesgo masculino: femenino fue 1.04 y 1.3 , respectivamente (34, 123).

\section{Distribución en los animales}

Se han identificado, usando métodos convencionales, ooquistes parecidos a los de C. cayetanensis en las heces de varios animales como patos (125), pollos (119, 128, 129), ratones, ratas $(119,128)$, perros $(119,130)$ y pájaros (131). En un zoológico de España, se observaron ooquistes parecidos a los de Cyclospora en animales carnívoros, artiodáctilos y primates no humanos (132). La presencia del coccidio también se ha demostrado por PCR en heces de un pollo, dos perros y un mono (133) 
$y$ en un mono Rhesus (134). Sin embargo, estos estudios no aportaron evidencia histológica de que el parásito invadiera el tejido intestinal. En contraste con estos resultados, Cyclospora no se detectó en Haití en 327 animales domésticos, como palomas, gallinas, patos, pavos, conejillos de India, gatos, perros, cabras, cerdos, caballos y ganado vacuno (135) y en Brasil, en 140 perros callejeros (136) y en Lima, Perú (137). Los intentos de infectar a varios animales con C. cayetanensis no han tenido éxito, sugiriendo la especificidad de hospedador (138). Aunque se reportó la propagación de $C$. cayetanensis en ratones albinos (139) y conejillos de India (47) los resultados no pudieron ser confirmados (18). El parásito ha sido detectado en crustáceos, en mariscos comercializados en Alejandría, Egipto (140) y en mejillones cultivados y silvestres de la provincia de Esmirna, Turquía (141). No existen datos en relación a los peces.

Los rotíferos, los insectos y los nematodos de vida libre podrían desempeñar un papel en la propagación de Cyclospora (18).

Los humanos son los únicos hospedadores conocidos de $C$. cayetanensis. Sin embargo, la propagación mecánica del parásito a través de los animales domésticos fue sugerida en áreas endémicas desde el comienzo. El contacto con los animales se ha considerado un factor de riesgo para la infección en Guatemala (28), Perú (121), Jordania (44), Nepal $(51,119,128)$ y Egipto (142).

\section{Distribución ambiental}

En áreas endémicas donde el sistema de tratamiento de aguas residuales, las instalaciones sanitarias y el desarrollo de viviendas estándar son insuficientes o inexistentes, los ooquistes de Cyclospora pueden propagarse con facilidad a través de los suministros y sistemas de distribución de agua, los alimentos y el suelo. En regiones tanto en desarrollo como desarrolladas, el parásito ha sido aislado de diversas matrices ambientales como aguas de consumo, de recreación y residuales; frutas y vegetales frescos y suelo (Tabla III).

\section{Agua de consumo}

En Nepal, se detectaron ooquistes de Cyclospora en el agua potable municipal la cual fue asociada a un brote en la región. El agua potable consistía en una mezcla de agua municipal y de río. No se detectaron bacterias coliformes sugiriendo que la cloración del agua tenia un nivel aceptable pero que no fue suficiente para quitarle la viabilidad al coccidio (63). En las zonas rurales de Guatemala, el parásito fue identificado, con técnicas moleculares, en 3 de 5 muestras de agua destinada al consumo público (146). En Vietnam, se identificaron ooquistes en agua potable (153). En Egipto, el coccidio fue aislado de $21 \%(64 / 300)$ de las muestras de agua potable en cinco zonas residenciales (160) y de $0,24 \%(2 / 840)$ de las muestras de agua de siete distritos (142). En Ghana, Accra, 59,3\% (16/27) de bolsas que contenían agua para el consumo tenían ooquistes (162). En España, se observó el parásito en agua potable (150). En Italia, el 30\% (3/10) de las muestras de agua de grifo recogida en un tren contenía copias de ADN correspondiente a 4-11 ooquistes por litro (151). Esta alta concentración es preocupante por la posibilidad de la presencia de ooquistes esporulados que tienen alta viabilidad (164) y dosis infectiva baja (165).

Algunos autores han reportado, en fuentes de agua potable y ambiental, la presencia de C. cayetanensis durante todo el año en Egipto $(142,160)$ y otros han detectado el coccidio con mayor prevalencia, pero no significativa, en la primavera en España (150) e Italia (151). En otro estudio de Italia, la mayor prevalencia del coccidio en el suelo, vegetales y aguas residuales fue en el otoño (152).

Vol. 59(1): 67 - 93, 2018 
TABLE III

AISLAMIENTO Y PREVALENCIA DE CYCLOSPORA EN MATRICES AMBIENTALES

\begin{tabular}{|c|c|c|c|}
\hline País & Matriz & $\begin{array}{l}\text { Contaminados } \\
\%(\mathrm{n} / \mathrm{n} \text { total })\end{array}$ & Referencia \\
\hline Canadá & Ensaladas pre-cortadas & $1,6(9 / 544)$ & (143) \\
\hline \multirow[t]{4}{*}{ Estados Unidos } & Ensalada de pollo, albahaca ${ }^{a}$ & $\mathrm{ND}^{\mathrm{b}}$ & (144) \\
\hline & Torta de frambuesas & ND & $(76)$ \\
\hline & PTAR c : afluente & $25,0(6 / 24)^{a}$ & $(145)$ \\
\hline & efluente & $12,5(3 / 24)^{a}$ & \\
\hline \multirow[t]{2}{*}{ Guatemala } & Ríos & $6,7(2 / 30)$ & $(28)$ \\
\hline & Agua potable & $41,7(5 / 12)^{\mathrm{a}}$ & $(146)$ \\
\hline Costa Rica & Lechuga & $4,0(2 / 50)$ & $(147)$ \\
\hline Venezuela & Lechuga & $5,9(6 / 102)$ & $(148)$ \\
\hline \multirow[t]{2}{*}{ Perú } & Vegetables & $1,7(3 / 172)$ & (137) \\
\hline & Aguas residual & $72,7(8 / 11)$ & (149) \\
\hline España & PTAP d, PTAR, río & $9,0(20 / 223)$ & $(150)$ \\
\hline \multirow[t]{5}{*}{ Italia } & Agua de inodoro ${ }^{\text {a }}$ & ND & $(151)$ \\
\hline & Vegetables, frutas & $12,2(6 / 49)^{a}$ & $(152)$ \\
\hline & Agua residual tratada & $21,3(20 / 94)^{a}$ & \\
\hline & Agua de pozo & $6,2(1 / 16)^{a}$ & \\
\hline & Suelo & $11,8(6 / 51)^{a}$ & \\
\hline \multirow[t]{5}{*}{ Nepal } & Agua potable & ND & $(63)$ \\
\hline & Vegetales de hojas verdes & ND & $(128)$ \\
\hline & Aguas residuales & ND & \\
\hline & Vegetales de hojas verdes & ND & (119) \\
\hline & Agua potable y residual & ND & \\
\hline \multirow[t]{2}{*}{ Vietnam } & Lagos, ríos & $63,6(84 / 132)^{a}$ & $(153)$ \\
\hline & Hierbas, agua & $10,1(58 / 575)$ & (154) \\
\hline Cambodia & Espinaca de agua & $8,3(3 / 36)$ & $(155)$ \\
\hline Corea del Sur & Vegetales & $1,2(5 / 404)^{a}$ & (156) \\
\hline Turquía & Crustáceos & $26,4(14 / 53)^{a}$ & $(141)$ \\
\hline Túnez & Aguas residuales & $0,4(1 / 232)^{a}$ & (157) \\
\hline Iraq & Suelo & $11,0(27 / 245)^{\mathrm{a}}$ & (158) \\
\hline \multirow[t]{5}{*}{ Egipto } & Vegetales de hojas verdes & ND & (159) \\
\hline & Mariscos & ND & $(140)$ \\
\hline & Agua potable, ríos & $0,2(2 / 840)$ & $(142)$ \\
\hline & Agua potable & $21,3(64 / 300)$ & $(160)$ \\
\hline & Vegetales verdes & ND & (161) \\
\hline \multirow[t]{2}{*}{ Ghana } & Bolsas de agua potable & $59,3 \%(16 / 27)$ & $(162)$ \\
\hline & Vegetales & $11,9(20 / 168)$ & (163) \\
\hline
\end{tabular}

aMétodos PCR; 'No determinado; 'Plantas de tratamiento de aguas residuales, Plantas de tratamiento de agua potable. 


\section{Agua de riego y cultivos}

En Guatemala (28), Vietnam (154) e Italia (152) el agua utilizada para el riego o para el procesamiento de verduras contenía ooquistes de Cyclospora. En Guatemala, el agua de río utilizada para el riego o la aplicación de insecticidas en los campos de cultivo de frambuesas contenía ooquistes y podría haber sido la fuente de contaminación de las frambuesas asociadas a varias epidemias en América del Norte (28). En Vietnam, 11,8\% (34/288) de las muestras de agua y hierbas como cilantro, mejorana, albahaca, lechuga y menta recogidas en mercados y 8\% (24/287) de las muestras de granjas fueron positivas para Cyclospora antes de la temporada de lluvias pero no durante este tiempo (154). Entre los productos frescos de mercados en Perú, $C$. cayetanensis fue detectada en albahaca, col, apio, cilantro, cebolla, ají, hierbas, ajo porro, puerros, lechuga y perejil (137).

En Canadá, se realizó el primer estudio a gran escala de vegetales de hojas verdes envasados listos para comer, para detectar la presencia de protozoos, utilizando la técnica de PCR, en América del Norte. Se obtuvieron 544 muestras de una variedad de tiendas de comestibles en Ontario, entre abril de 2009 y marzo de 2010; la mayoría de estos productos fueron cultivados en USA y algunos en Canadá y México. Se observó una prevalencia de 1,7\% (9/544) de Cyclospora. Este resultado estableció una línea base para futuros estudios y sugirió la necesidad de más investigaciones en relación con las posibles fuentes de contaminación de estos alimentos, la evaluación de la viabilidad del parásito y las estrategias para reducir la transmisión de éste a través de los alimentos (143).

En USA (144), Costa Rica (147), Venezuela (148), Nepal (119, 128), Vietnam (154), Cambodia (155) y Egipto $(159,161)$, también se detectaron ooquistes en vegetales de hojas verdes. En USA, el parásito fue encontrado en el relleno de frambuesa de una torta (76).

En Costa Rica y Venezuela, el parásito fue identificado en lechugas. En Costa Rica, Cyclospora se detectó durante la estación seca $(147,148)$. En Ghana, el coccidio fue aislado de repollo, pimentón, zanahoria, cebolla, tomate y lechuga (163). La relación entre el número de organismos encontrados en productos frescos y la cifra en el entorno en que fueron cultivados es incierta (2).

\section{Agua de mar}

No se ha reportado la presencia de Cyclospora en el agua de mar. Sin embargo, la detección de ooquistes en crustáceos sugiere la contaminación de las aguas costeras en algunas áreas $(140,141)$.

\section{Aguas superficiales}

En aguas de ríos y lagos de Guatemala, Vietnam, Egipto y España se identificaron ooquistes del coccidio $(28,142,150,153)$. En las aguas superficiales, la ocurrencia de ooquistes puede ser muy variable pero con baja frecuencia. La concentración estimada del parásito en los ríos de Guatemala fue de 15.000 o más ooquistes por muestra de 10 litros (28).

\section{Aguas subterráneas}

La información acerca de la presencia de Cyclospora en aguas subterráneas es escasa. En Egipto, el coccidio se aisló en cinco zonas residenciales, de un desagüe, un canal de irrigación, agua subterránea y agua de cañería, lo que refleja la alta contaminación ambiental de la zona (142). En Italia, se identificaron ooquistes en $6,2 \%(1 / 16)$ de las muestras de agua de pozo (152).

\section{Aguas residuales}

En Perú, 72,7\% (8/11) de las muestras de agua de una laguna de oxidación primaria contenían Cyclospora (149). También fue 
detectada en aguas residuales en Nepal (119, 128) y Túnez (157). En España, se aislaron ooquistes en plantas de tratamiento de aguas residuales con una prevalencia anual de 16,1\% $(9 / 56)$ en agua cruda y $10,7 \%(6 / 56)$ en el agua tratada. La mayor prevalencia se observó en la primavera (150). En Italia, se detectaron ooquistes en $21,3 \%(20 / 94)$ de muestras de aguas residuales, principalmente en el otoño (152). En USA (Arizona), los ooquistes fueron encontrados en dos plantas de tratamiento de aguas residuales tanto en el agua cruda como en la tratada (145).

\section{Lodo}

No existen datos al respecto.

\section{Suelo}

En estudios realizados con técnicas moleculares en Apulia, Italia (152) y en Iraq (158), 11,8\% (6/51) y 11\% (27/245) de las muestras de suelo estudiadas, respectivamente, tenían ooquistes del parásito.

De acuerdo a los datos presentados en la Tabla III, se puede inferir que el coccidio tiene una distribución ambiental amplia, que es frecuente incluso en algunas zonas de los países industrializados y que el agua y el suelo pueden representar también una fuente de infección en estas regiones. En Madrid, España, se detectaron ooquistes de Cyclospora en el 9\% de muestras de agua potable y aguas recreacionales y residuales (150) y en el 15,5\% de varias matrices medioambientales incluyendo aguas residuales tratadas, suelos y vegetales en Apulia, sur de Italia, con una alta prevalencia de la infección en humanos $(27,5 \%, 11 / 40)$ (152). En el sur de Arizona, USA, el 19\% de las muestras de las aguas residuales presentaron el parásito (145). El hallazgo del parásito en diferentes muestras ambientales en España, Italia y USA sugieren que éstas pueden representar una fuente de infección en estas áreas y el potencial de $C$. cayetanensis a ser endémica en ciertas áreas en los países industrializados. El estudio sobre la presencia del coccidio en aguas residuales tratadas de Arizona sugiere que la infección es frecuente en esta área. Es concebible la existencia de algunas infecciones por Cyclospora transmitidas por el agua en los países desarrollados ya que varios brotes han sido atribuidos al agua $(40,65,66)$.

\section{CONTROL}

\section{Prevención}

Las medidas preventivas son el enfoque más efectivo para el control de $C$. cayetanensis. Puesto que las fuentes de infección humana son los alimentos, el agua y los suelos contaminados, la aplicación de medidas para disminuir o evitar la diseminación de los ooquistes en el medio ambiente es fundamental. El mejoramiento de la higiene personal y el saneamiento ambiental puede reducir la exposición a las heces humanas y la contaminación del medio ambiente. El lavado de los alimentos puede reducir el riesgo de adquirir la infección pero no elimina por completo el parásito de los productos contaminados y el riesgo de contraer la infección $(72,73)$. De hecho, algunos ooquistes permanecen en el producto después del lavado (137).

En el mundo en desarrollo, los pasos más importantes para prevenir la infección son la educación para la salud, la higiene personal, el adecuado lavado de las manos y de los productos frescos, el cambio de hábitos de consumo de alimentos, el suministro de agua potable, infraestructuras sanitarias adecuadas y el tratamiento de las aguas residuales. Sin embargo, estos pasos son retos difíciles para los países de ingresos bajos por lo cual las parasitosis intestinales en general constituyen un problema de salud pública persistente (166). La prevención de la geofagia en niños es importante 
debido a la transmisión de la infección a través del contacto con suelos contaminados (34).

La relación entre la marginalidad social y la ciclosporiasis conlleva importantes implicaciones para las intervenciones de salud pública para evitar la infección en grupos de escasos recursos (6), al igual que en otras parasitosis intestinales $(167,168)$. Una mayor familiaridad con el parásito y la enfermedad mejoraría los programas de vigilancia para el coccidio y aumentaría la probabilidad de la detección temprana de epidemias futuras. Es necesario implementar técnicas de detección en los laboratorios y en el campo que ayuden a controlar la infección y prevenir brotes locales y asociados a productos importados contaminados en el mundo desarrollado. La comprensión de las interacciones socioeconómicas y ambientales junto con estudios longitudinales y de tipificación genética serán la clave para orientar las estrategias de prevención y control de la infección $(6,169)$.

Para la prevención de la ciclosporiasis transmitida por el agua se pueden seguir las instrucciones y normas desarrolladas por las organizaciones internacionales para el control de protozoos transmitidos por el agua. Desde una perspectiva de salud pública, la propagación potencial del parásito por el agua solamente puede evitarse por un tratamiento adecuado de las fuentes de agua en el hogar. Son recomendables los estudios para evaluar la calidad del agua almacenada y las prácticas domésticas que estimulan la contaminación de ésta después de su tratamiento. Los consumidores deben ser conscientes de los riesgos asociados con el consumo de verduras y frutas crudas sin lavar. Para el lavado de éstas y la preparación de alimentos para el consumo se debe utilizar agua filtrada o hervida.

El uso de aguas residuales y excretas en la producción agrícola puede facilitar la diseminación de parásitos e impactar la salud humana; los riesgos de salud más comunes son las enfermedades diarreicas y los patógenos transmitidos por el suelo (53). La identificación de $C$. cayetanensis en aguas residuales $(119,128$, $149,157)$ indica que es necesario el desarrollo de medidas para reducir al mínimo la exposición humana a este protista y para mejorar la seguridad de la descarga y el reuso de aguas residuales y lodos. El uso de estiércol como fertilizante en las granjas puede producir contaminación cuando no es tratado correctamente. La calidad del agua utilizada para el riego de los cultivos y el lavado de los productos después de la cosecha es esencial para preservar la higiene en las operaciones de cultivo. Los agricultores deben ser educados sobre los riesgos del uso de las aguas residuales y aguas contaminadas para el riego de cultivos de frutas y verduras. Se deben proporcionar servicios sanitarios para los recolectores y manipuladores de las cosechas $(6,77)$.

En el mundo desarrollado, los consumidores deben ser conscientes de los riesgos asociados con el consumo de productos frescos sin lavar. Es necesario la implementación y el seguimiento de medidas de control en las fincas en áreas endémicas para evitar o disminuir futuras epidemias localmente y en áreas industrializadas. Las buenas prácticas agrícolas e industriales y la coordinación global son importantes para prevenir la introducción del patógeno en los productos agrícolas. Los productos pueden contaminarse en el campo durante la recolección, almacenamiento o transporte. Por lo tanto, se deben idear métodos de control para las rutas posibles usadas por el coccidio para entrar en el proceso de la producción de alimentos $(2,3)$.

Debido a los cambios en el procesamiento de los productos, más alimentos son pre-cortados y empacados en el campo durante la cosecha, aumentando la probabilidad de contaminación (143). Para evitar la contaminación de los alimentos, es necesario el establecimiento de

Vol. 59(1): 67 - 93, 2018 
medidas preventivas o de control en la operación del procesamiento y producción de alimentos crudos entrando o dentro de la fábricas $(2,3)$. Las buenas prácticas agrícolas y de manufactura y la coordinación global son importantes para prevenir la introducción del patógeno en los productos agrícolas. El hacer cumplir las leyes del comercio internacional de alimentos y la implementación de métodos que usen los acuerdos de puntos de control críticos pueden ayudar en el control de la infección (5).

Las epidemias multi-estatales de ciclosporiasis ocurridas en USA en 2013-2015 (Tabla II), se relacionaron con cilantro fresco de Puebla, México. Como consecuencia, la Administración de Drogas y Alimentos (FDA) de USA y el gobierno de México implementaron controles de seguridad para este producto en ambos lados de la frontera. La FDA implementó controles de importación para la detención sin examen físico de las embarcaciones con envíos de cilantro fresco del estado de Puebla. Los controles implementados por México incorporaron un sistema de reducción de riesgos, incluidos los controles de exportación de cilantro de ese estado. Los productores de cilantro deben cumplir con 11 requisitos mínimos de buenas prácticas agrícolas y de seguridad de alimentos (170). Este esfuerzo colaborativo aseguraría que las frutas y las verduras frescas esten siendo preparadas y almacenadas en condiciones sanitarias.

\section{Descontaminación}

Se sabe muy poco acerca del control de $C$. cayetanensis mediante las técnicas sanitarias. En la actualidad no hay disponibilidad de técnicas de desinfección para descontaminar los productos lo cual mejoraría la seguridad y la calidad de los alimentos importados. Los ooquistes son resistentes a muchos desinfectantes, incluyendo la cloración a los niveles utilizados en el tratamiento del agua (63). La esporulación de los ooquistes no es inactivada cuando se exponen a insecticidas como captán $50 \%$ en polvo humectable (P. H), benomilo $50 \% \mathrm{P}$. H, diazinón $47,5 \%$, malatión o paraquat $25 \% \mathrm{P}$. $\mathrm{H}$ y zineb $75 \%$ P. H, a dosis inferiores y superiores a las recomendadas (18).

En los países desarrollados, se ha demostrado que la eficacia de los procesos convencionales de tratamiento de aguas residuales en la eliminación de ooquistes de Cyclospora es limitada (145, $150,152)$. Estos resultados apoyan la idea de que tratamientos más avanzados como la ultrafiltración de membrana, la desinfección con rayos ultravioleta o el manejo de la recarga de acuíferos serán requeridos para una mayor reducción de ooquistes para propósitos de recuperación (145). Tecnologías avanzadas de ultrafiltración de membrana y radiación con rayos ultravioleta previenen el pasaje de ooquistes (152). La posibilidad de que parásitos emergentes como Cyclospora y los hongos microsporidios sobrevivan varios tratamientos de bio-sólidos es baja, debido a que no resistirían las temperaturas alcanzadas en la digestión anaeróbica y no sobrevivirían en condiciones de baja humedad (171).

Debido a la falta de modelos animales o de infectividad in vitro, la esporulación de los ooquistes se ha utilizado como indicador de viabilidad. Se han evaluado métodos para matar a los parásitos que dependen de la temperatura y el tiempo de almacenamiento. La exposición a temperatura alta de $96^{\circ} \mathrm{C}$ por $45 \mathrm{~s}$ no impidió totalmente la esporulación de Cyclospora (172). Para substratos lácteos, el almacenamiento a $-15^{\circ} \mathrm{C}$ por 24 horas no inactivó los ooquistes de Cyclospora. Para el agua o la albahaca, el almacenamiento a $-20^{\circ} \mathrm{C}$ por 2 días, $50^{\circ} \mathrm{C}$ por 1 hora y $37^{\circ} \mathrm{C}$ durante 4 días no impidió la esporulación; sin embargo, las temperaturas extremas $\left(70^{\circ} \mathrm{C},-70^{\circ} \mathrm{C}\right.$ y $\left.100^{\circ} \mathrm{C}\right)$ fueron eficaces en prevenir la esporulación de los ooquistes. Las temperaturas usualmente usadas 
para almacenar los productos de 4 a $23^{\circ} \mathrm{C}$, no afectan la esporulación de Cyclospora (173). El calentamiento en microondas puede inactivar los ooquistes pero el dióxido de cloro gaseoso a 4,1 mg/litro no afecta la esporulación de Cyclospora; sin embargo, este tratamiento inactiva a Cryptosporidium y microsporidios (18).

La falta de métodos in vivo $\mathrm{o}$ in vitro para probar la viabilidad de los ooquistes de Cyclospora ha llevado a los investigadores a utilizar substitutos del parásito, como Eimeria acervulina, un coccidio de pollos con semejanzas a Cyclospora, y Toxoplasma para desarrollar tratamientos de descontaminación de frutas importadas de áreas endémicas. La congelación, el calentamiento y la radiación gamma, a dosis de 1,0 kGy o superior (174) y los tratamientos con alta presión hidrostática $\left(550 \mathrm{MPa}\right.$ a $40^{\circ}$ $\mathrm{C}$ por $2 \mathrm{~min}$ ) y radiación con luz ultravioleta (hasta $261 \mathrm{~mW} / \mathrm{cm}^{2}$ ) de productos contaminados con E. acervulina (175) sugieren su utilidad en reducir el riesgo de ciclosporiasis asociadas a productos contaminados. Sin embargo, estos dos últimos tratamientos no lograron inactivar completamente los ooquistes de las matrices de alimentos. La irradiación con rayos gamma (137Cs) de ooquistes de Toxoplasma se evaluó como un sistema modelo de inactivación de ooquistes de Cyclospora. Los ooquistes tratados con $\geq 0,4 \mathrm{kGy}$ esporularon e infectaron células pero no causaron infecciones en ratones. Se recomendó que $0,5 \mathrm{kGy}$ se utilizara para matar los ooquistes de coccidios en las frutas y verduras. Ooquistes de Toxoplasma (cepa VEG) inoculados en frambuesas no infectaron ratones después de ser tratados con alta presión hidrostática $(340 \mathrm{MPa})$ durante 60 segundos (18).

Este parásito enigmático con sus características únicas ha desafiado a nuestra capacidad para entender su dinámica de transmisión y para desarrollar estrategias efectivas de control. Se conoce poco sobre la biología ambiental de $C$. cayetanensis y se desconocen los factores que favorecen o impiden la esporulación y los que determinan la variación estacional de la infección. No está claro cómo los ooquistes son diseminados o transferidos de un hospedador a otro. La larga duración de la esporulación y el período pre-patente del coccidio dificultan las investigaciones de rastreo de las epidemias para la identificación de los factores de riesgo y vehículos de transmisión de la infección. Los modos de diseminación de la ciclosporiasis, que son esenciales para conocer los factores de riesgo para la infección y para establecer las estrategias de prevención, no se saben completamente. En los países en desarrollo, podrían existir múltiples rutas de transmisión. En estas áreas, las infecciones vinculadas al contacto con el suelo sugieren que esta vía de diseminación puede ser más común de lo que se cree. La frecuencia con la cual esta ruta de transmisión ocurre y si las variables asociadas con el nivel socioeconómico podrían predisponer a las personas a la infección ameritan ser estudiadas en diferentes regiones.

La creciente globalización del suministro de alimentos frescos y el comercio internacional son factores de complicación en la prevención y control de la ciclosporiasis en los países desarrollados. Al igual que los mercados globales se expanden, también lo hace el potencial de la transmisión de la infección por los alimentos. Las epidemias multi-estatales, asociadas con alimentos, de 2013 al 2015 en USA y Canadá $(95,96,98,100,101)$ indican que es necesaria una vigilancia adicional. Sin embargo, el control de $C$. cayetanensis en las operaciones de fabricación y servicio de alimentos es difícil.

La falta de cultivos para el parásito y de datos de secuencia del mismo ha dificultado el desarrollo de métodos de detección adecuados. La caracterización molecular de los aislados en matrices ambientales junto

Vol. 59(1): 67 - 93, 2018 
con el rastreo de la fuente de la infección y el seguimiento de la enfermedad podrían mejorar enormemente nuestro conocimiento de las rutas de contaminación y medidas de prevención y control. La secuencia del genoma contribuirá significativamente al desarrollo de métodos moleculares confiables de tipificación para las investigaciones de los brotes. Se están realizando estudios para producir datos de la secuencia total del genoma del parásito para facilitar el desarrollo de marcadores genéticos fiables para su uso en la taxonomía, filogenia, diagnóstico y control. El reciente desarrollo de una herramienta para tipificar el parásito (169) podría ayudar a determinar el origen de los casos y brotes de la infección y las respuestas de salud pública y de las agencias reguladoras.

Se requiere el desarrollo de nuevos métodos simples y rápidos para determinar la viabilidad de $C$. cayetanensis y mejorar las técnicas de desinfección de productos contaminados. La aplicación de estas tecnologías de avance mejorará la calidad y seguridad de los alimentos y el agua. Deben hacerse esfuerzos para asegurar que los avances tecnológicos también se apliquen en países de bajos ingresos donde es mayor la carga de la ciclosporiasis.

\section{CONCLUSIONES Y RECOMENDACIONES}

La aplicación de medidas para disminuir o evitar la diseminación de Cyclospora en el medio ambiente es fundamental. Los países industrializados deben asumir un papel activo en ayudar a los países donde la enfermedad es endémica para mejorar las prácticas para minimizar el riesgo de alimentos contaminados. Son necesarios la implementación y el seguimiento de medidas de control en las fincas en áreas endémicas para evitar o disminuir futuras epidemias localmente $\mathrm{y}$ en áreas industrializadas. Las buenas prácticas agrícolas y de manufactura y la coordinación global son importantes para prevenir la introducción del patógeno en los productos agrícolas. La seguridad alimentaria en todo el mundo es una necesidad absoluta para cerciorarse del suministro de alimentos y agua de calidad para los consumidores internacionales. El hacer cumplir las leyes del comercio internacional de alimentos y la implementación de métodos que usen los acuerdos de puntos de control críticos pueden ayudar en el control de la infección.

Es preciso desarrollar sistemas in vitro o in vivo para la propagación de Cyclospora para comprender mejor la biología y epidemiología del parásito, nuevos métodos para determinar la viabilidad del coccidio y técnicas de desinfección eficientes para descontaminar los productos. La secuencia del genoma del parásito facilitará el desarrollo de marcadores genéticos fiables para su uso en la taxonomía, filogenia, diagnóstico y control. Los estudios longitudinales y de tipificación del coccidio junto con la comprensión de las interacciones socioeconómicas y ambientales serán la clave para orientar las estrategias de prevención y control de la ciclosporiasis.

\section{REFERENCIAS}

1. Chacín-Bonilla L. Epidemiology of Cyclospora cayetanensis: A review focusing in endemic areas. Trans R Soc Trop Med Hyg. 2010;115: 181-193.

2. Dawson D. Foodborne protozoan parasites. Int J Food Microbiol 2005; 103: 207-227.

3. Keller SE. Microbial contamination of fresh produce. In Intentional and unintentional contaminants in food and feed, vol 1020. American Chemical Society, Eds. Washington, DC. 2009. P 25-45.

4. Gervelmeyer A, Hempen $M$, Nebel U, Weber C, Bronzwaer S, Ammon A, Makela P. Developing the community 
reporting system for food borne outbreaks. Euro Surveill 2008 Nov; 13 (45). Available online: http://www.eurosurveillance.org/ ViewArticle.aspx?ArticleId=19029.

5. Buisson Y, Marie JL, Davoust B. These infectious diseases imported with food. Bull Soc Pathol Exot 2008; 101: 343-347.

6. Chacín-Bonilla, L. Cyclospora cayetanensis. In: Rose JB, Jiménez- Cisneros B, Eds. Global Water Pathogens Project. http://www.waterpathogens.org (Fayer R, Jakubowski W, Eds. Part 3 Protists) http:// www.waterpathogens.org/book/cyclosporacayetanensis Michigan State University, E. Lansing, MI, UNESCO. 2017.

7. Velasquez JN, Carnevale S, Cabrera $M$, Kuo L, Chertcoff A, Mariano M Bozzini JP, Etchart C, Argento R, di Rissio C. Cyclospora cayetanensis en pacientes con SIDA y diarrea crónica. Acta Gastroenterol Latinoam 2004; 34: 133-137.

8. Iqbal J, Hira PR, Al-Ali F, Khalid N. Cyclospora cayetanensis: first report of imported and autochthonous infections in Kuwait. Infect Dev Ctries 2011; 5: 383-390.

9. Albert MJ, Kabir I, Azim T, Hossain A, Ansaruzzaman M, Unicomb L. Diarrhea associated with Cyclospora sp. in Bangladesh. Diagn Microbiol Infect Dis 1994; 19: 47-49.

10. Berlin OG, Novak SM, Porschen RK, Long EG, Stelma GN, Schaeffer III FW. Recovery of Cyclospora organisms from patients with prolonged diarrhea. Clin Infect Dis 1994; 18: 606-609.

11. Markus MB, Frean JA. Occurrence of human Cyclospora infection in sub-Saharan Africa. S Afr Med J 1993; 83: 862-863.

12. Wurtz RM, Kocka FE, Peters CS, Weldon-Linne CM, Kuritza A, Yungbluth P. Clinical characteristics of seven cases of diarrhea associated with a novel acid-fast organisms in the stool. Clin Infect Dis 1993;
16: 136-138.

13. Green ST, McKendrick MW, Mohsen AH, Schmid ML, Prakasam SF. Two simultaneous cases of Cyclospora cayetanensis enteritis returning from Dominican Republic. J Travel Med 2000; 7: 41-42.

14. Estran C, Chaillou S, Marty P. Un risque parasitaire pour le touriste en Republique Dominicaine: la cyclosporose. Med Trop 2004; 64: 98-99.

15. Weitzel T, Wichmann O, Mühlberger N, Reuter B, Hoof HD, Jelinek T. Epidemiological and clinical features of travel-associated cryptosporidiosis. Clin Microbiol Infect 2006; 12: 921-924.

16. Cedeño TC. Cyclospora cayetanensis: descripción del primer caso en el Hospital San Rafael de Alajuela. Acta Méd Costarric 2002; 44: 79-81.

17. Drenaggi D, Cirioni O, Giacometti A, Fiorentini A, Scalise G. Cyclosporiasis in a traveler returning from South America. J Travel Med 1998; 5: 153-155.

18. Ortega YR, Sanchez R. Update on Cyclospora cayetanensis, a food-borne and waterborne parasite. Clin Microbiol Rev 2010; 23: 218-34.

19. Gascon J, Corachan M, Bombi JA, Valls ME, Bordes JM. Cyclospora in patients with traveller's diarrhea. Scand J Infect Dis 1995; 27: 511-514.

20. Lebbad M, Linder E. Newly discovered organism behind diarrhea. All patients had recently been abroad. Lakartidningen 1993; 90: 951-952.

21. Pollok RC, Bendall RP, Moody A, Chiodini PL, Churchill DR. Traveller's diarrhoea associated with Cyanobacteriumlike bodies. Lancet 1992; 340: 556-557.

22. Rijpstra AC, Laarman JJ. Repeated findings of unidentified small Isospora-like coccidia in faecal specimens from travellers

Vol. 59(1): 67 - 93, 2018 
returning to The Netherlands. Trop Geogr Med 1993; 45: 280-282.

23. Deluol AM, Junod C, Poirot JL, Heyer F, N'go Y, Cosnes J. Travellers diarrhea associated with Cyclospora sp. J Eukaryot Microbiol 1994; 41: 32S.

24. Bouree P, Lancon A, Bisaro F, Bonnot G. Six human cyclosporiasis: with general review. J Egypt Soc Parasitol 2007; 37: 349360.

25. Lalonde LF, Reyes J, Gajadhar AA. Application of a qPCR assay with melting curve analysis for detection and differentiation of protozoan oocysts in human fecal samples from Dominican Republic. Am J Trop Med Hyg 2013; 89: 892-898.

26. Diaz E, Mondragon J, Ramirez E, Bernal R. Epidemiology and control of intestinal parasites with nitazoxanide in children in Mexico. Am J Trop Med Hyg 2003; 68: 384385.

27. Orozco-Mosqueda GE, Martínez-Loya OA, Ortega YR. Cyclospora cayetanensis in a pediatric hospital in Morelia, México. Am J Trop Med Hyg 2014; 91: 537-540.

28. Bern C, Hernandez B, Lopez MB, Arrowood MJ, Alvarez de Mejia M, de Merida AM, Hightower AW, Venczel L, Herwaldt BL, Klein RE. Epidemiologic studies of Cyclospora cayetanensis in Guatemala. Emerg Infect Dis 1999; 5: 766774.

29. Kaminsky RG. Comparación epidemiológica entre apicomplexa intestinales en población hospitalaria en Honduras. Rev Med Hondur 2002; 70: 164172.

30. Nuñez FA, Gonzalez OM, Gonzalez I, Escobedo AA, Cordovi RA. Intestinal coccidia in Cuban pediatric patients with diarrhea. Mem Inst Oswaldo Cruz 2003; 98 : 539-542.
31. Lopez AS, Bendik JM, Alliance JY, Roberts JM, da Silva AJ, Moura IN, Arrowood MI, Eberhard ML, Herwaldt BL. Epidemiology of Cyclospora cayetanensis and other intestinal parasites in a community in Haiti. J Clin Microbiol 2003; 41: 2047-2054.

32. Chacin-Bonilla L, Estevez J, Monsalve F, Quijada L. Cyclospora cayetanensis infections among diarrheal patients from Venezuela. Am J Trop Med Hyg 2001; 65: 351-354.

33. Chacin-Bonilla L, Mejia de Young M, Estevez J. Prevalence and pathogenic role of Cyclospora cayetanensis in a Venezuelan community. Am J Trop Med Hyg 2003; 68: 304-306.

34. Chacin-Bonilla, L., Barrios, F., Sanchez, Y.Epidemiology of Cyclospora cayetanensis infection in San Carlos Island, Venezuela: strong association between socio-economic status and infection. Trans R Soc Trop Med Hyg 2007; 101:1018-1024.

35. Cazorla D, Acosta ME, Acosta ME, Morales P. Estudio clínico-epidemiológico de coccidiosis intestinales en una población rural de región semiárida del estado Falcón, Venezuela. Invest Clin 2012; 53: 273-288.

36. Dias Borges J, Rodriguez Alarcon RS, Amato Neto, V, Gakiya. Parasitoses intestinais de indigenas da comunidade Mapuera (Oriximina, Estadodo Para, Brasil): elevada prevalencia de Blastocystis hominis and finding of Cryptosporidium sp. and Cyclospora cayetanensis. Rev Soc Bras Med Trop 2009; 42: 348-350.

37. Ortega YR, Sterling CR, Gilman RH, Cama VA, Diaz F. Cyclospora species a new protozoan pathogen of humans. N Engl J Med 1993; 328: 1308-1312.

38. Madico G, McDonald J, Gilman RH, Cabrera L, Sterling CR. Epidemiology and treatment of Cyclospora cayetanensis 
infection in Peruvian children. Clin Infect Dis 1997; 24: 977-981.

39. Burstein-Alva S. Ciclosporosis: una parasitosis emergente. (1) Aspectos clínicos y epidemiológicos. Rev Gastroenterol (Perú) 2005; 25: 328-335.

40. Aksoy U, Tunkay S. Short communication: investigation of intestinal coccidia in patients with diarrhea. Mikrobiyol Bul 2007; 41: 127-131.

41. Karaman U, Daldal N, Ozer A, Enginyurt O, Erturk O. Epidemiology of Cyclospora species in humans in Malatya Province in Turkey. Jundishapur J Microbiol 2015 Jul; 8(e18661). Available online: https:// www.ncbi.nlm.nih.gov/pmc/articles/ PMC4584132/

42. El Fatni C, Olmo F, el Fatni H, Romero D, Rosales MJ. First genotyping of Giardia duodenalis and prevalence of enteroparasites in children from Tetouan (Morocco). Parasite 2014 Sep; 21(48). Available online: https://www.ncbi.nlm.nih.gov/pmc/articles/ PMC4176428/

43. Nassef NE, el-Ahl SA, el-Shafee OK, Nawar M. Cyclospora: a newly identified protozoan pathogen of man. J Egypt Soc Parasitol 1998; 28: 213-219.

44. Nimri LF. Cyclospora cayetanensis and other intestinal parasites associated with diarrhea in rural area of Jordan. Int Microbiol 2003; 6: 131-135.

45. Al-Braiken FA, Amin A, Beeching NJ, Hommel M, Hart CA. Detection of Cryptoporidium amongst diarrhoeic and asymptomatic children in Jeddah, Saudi Arabia. Ann Trop Med Parasitol 2003; 97: 505-510.

46. Gupta AK. Intestinal coccidian parasitic infections in rural community in and around Loni, Maharashtra. J Parasit Dis 2011; 35: 54-56.

47. Wang KX, Li CP, Wang J, Tian Y.
Cyclospora cayetanensis in Anhui China. World J Gastroenterol 2002; 8: 1144-1148.

48. Liu H, Shen Y, Yin J, Yuan Z, Jiang Y, Xu Y, Pan W, Hu Y, Cao J. Prevalence and genetic characterization of Cryptosporidium, Enterocytozoon, Giardia and Cyclospora in diarrheal outpatients in China. BMC Infect Dis 2014; 14: doi: 10.1186/1471-2334-1425.

49. Kimura K, Rai SK, Rai G, Insisiengmay S, Kawabata M, Karanis P, Uga S. Study on Cyclospora cayetanensis, associated with diarrheal disease in Nepal and Lao PDR. Southeast Asian J Trop Med Public Health 2005; 36: 1371-1376.

50. Tandukar S, Ansari S, Adhikari N, Shrestha A, Gautam J, Sharma B, Rajbhandari D, Gautam S, Nepal HP, Sherchand JB. Intestinal parasitosis in school children of Lalitpur district of Nepal. BMC Res Notes 2013; 6: 449. doi: 10.1186/1756-0500-6-449.

51. Bhandari D, Tandukar S, Parajuli H, Thapa P, Chaudhary $P$, Shrestha D, Shah PK, Sherchan JB, Sherchand JB. Cyclospora infection among the school children of Kathmandu, Nepal: prevalence and associated risk factors. Trop Med Health 2015; 43: 211-216.

52. Haque R, Mondal D, Kirkpatrick BD, Akther S, Farr BM, Bradley Sack R, Petri Jr, WA. Epidemiologic and clinical characteristics of acute diarrhea with emphasis on Entamoeba histolytica infections in preschool children in an urban slum of Dhaka, Bangladesh. Am J Trop Med Hyg 2003; 69: 398-405.

53. Pham-Duc $P$, Nguyen-Viet $H$, Hattendorf J, Zinsstag J, Phung-Dac C, Zurbrügg C, Odermatt P. Ascaris lumbricoides and Trichuris trichiura infections associated with wastewater and human excreta use in agriculture in Vietnam. Parasitol Int 2013;

Vol. 59(1): 67 - 93, 2018 
62:172-180.

54. Thima K, Mori H, Praevanit R, Mongkhonmu S, Waikagul J, Watthanakulpanich D. Recovery of Cyclospora cayetanensis among asymptomatic rural Thai schoolchildren. Asian Pac J Trop Med 2014; 7:119-123.

55. Fryauff DJ, Krippner R, Prodjodipuro P, Ewald C, Kawengian S, Pegelow K, YunT, von Heydwolff-Wehnert C, Oyofo B, Gross R. Cyclospora cayetanensis among expatriate and indigenous populations of West Java Indonesia. Emerg Infect Dis 1999; 5: 585-588.

56. Alakpa GE, Clarke SC, FagbenroBeyioku AF. Cyclospora cayetanensis in stools submitted in hospitals in Lagos, Nigeria. Clin Microbiol Infect 2003; 9: 731733.

57. Chacin-Bonilla L, Panunzio AP, Monsalve Castillo F, Parra Cepeda IE, Martinez R. Microsporidiosis in Venezuela. Prevalence of intestinal microsporidiosis and its contribution to diarrhea in groups of human immunodeficiency virus infected patients from Zulia State. Am J Trop Med Hyg 2006; 74: 482-486.

58. Arzuza OS, Arroyo BJ, Villegas S, Rocha A, Diaz H. Infecciones parasitarias intestinales en pacientes positivos para el virus de la inmunodeficiencia humana (VIH) en la ciudad de Cartagena de Indias, Colombia. Infection 2003; 7: 58-63.

59. Al-Megrin WA. Intestinal parasites infection among immunocompromised patients in Riyadh, Saudi Arabia. Pakistan J Biol Sci 2010; 13: 390-394.

60. Asma I, Johari S, Sim BL, Lim YA. How common is intestinal parasitism in HIVinfected patients in Malaysia? Trop Biomed 2011; 28: 400-410.

61. Cegielski JP, Ortega YR, McKee S, Madden JF, Gaido L, Schwartz DA,
Manji K, Jorgensen AF, Miller SE, Pulipaka UP, Msengi AE, Mwakyusa DH, Sterling CR, Reller LB. Cryptosporidium, Enterocytozoon, and Cyclospora infections in pediatric and adult patients with diarrhea in Tanzania. Clin Infect Dis 1999; 28: 314321.

62. Nsagha DS, Njunda AL, Assob NJ, Ayima CW, Tanue EA, Kibu OD, Kwenti TE. Intestinal parasitic infections in relation to CD4 (+) T cell counts and diarrhea in HIV/ AIDS patients with or without antiretroviral therapy in Cameroon. BMC Infect Dis 2016 Jan; 16 (9). Available online:https:// bmcinfectdis.biomedcentral.com

63. Rabold JG, Hoge CW, Shlim DR, Kefford C, Rajah R, Echeverria P. Cyclospora outbreak associated with chlorinated drinking water. Lancet 1994; 344:13601361.

64. Shlim DR, Cohen MT, Eaton M, Rajah R, Long EG, Ungar BL. An alga-like organism associated with an outbreak of prolonged diarrhea among foreigners in Nepal. Am J Trop Med Hyg 1991; 45: 383-389.

65. Huang P, Weber JT, Sosin DM, Griffin PM, Long EG, Murphy JJ, Kocka F,Peters C, Kallick C. The first reported outbreak of diarrheal illness associated with Cyclospora in the United States. Ann Intern Med 1995; 123: 409-414.

66. Hoge CW, Shlim DR, Rajah R, Triplett J, Shear M, Rabold JG, Echeverria P. Epidemiology of diarrhoeal illness associated with coccidian-like organism among travellers and foreign residents in Nepal. Lancet 1993; 341: 1175-1179.

67. Koumans EH, Katz DJ, Malecki JM, Kumar S, Wahlquist SP, Arrowood MJ, Hightower AW, Herwaldt BL. An outbreak of cyclosporiasis in Florida in 1995: a harbinger of multistate outbreaks in 1996 and 1997. Am J Trop Med Hyg 1998; 59: 


\section{5-242.}

68. Herwaldt BL. Cyclospora cayetanensis: a review focusing on the outbreaks of cyclosporiasis in the 1990s. Clin Infect Dis 2000; 31: 1040-1057.

69. Fleming CA, Caron D, Gunn JE, Barry MA. A foodborne outbreak of Cyclospora cayetanensis at a wedding: clinical features and risk factors for illness. Arch Intern Med 1998; 158: 1121-1125.

70. Herwaldt BL, Ackers ML. An outbreak in 1996 of cyclosporiasis associated with imported raspberries. N Engl J Med 1997; 336: 1548-1556.

71. Centers for Disease Control and Prevention (CDC). Outbreaks of cyclosporiasis-United States, 1997. MMWR Morb Mortal Wkly Rep 1997; 46: 451-452.

72. Herwaldt BL, Beach MJ. The return of Cyclospora in 1997: another outbreak of cyclosporiasis in North America associated with imported raspberries. Ann Intern Med 1999; 130: 210-220.

73. Centers for Disease Control and Prevention (CDC). Outbreak of cyclosporiasis-Northern VirginiaWashington, D.C.-Baltimore, Maryland, metropolitan area, 1997. MMWR Morb Mortal Wkly Rep 1997; 46:689-692.

74. CentersforDisease Controland Prevention (CDC). Outbreak of cyclosporiasis-Ontario, Canada, May 1998. MMWR Morb Mortal Wkly Rep 1998; 47: 806-809.

75. Lopez AS, Dodson DR, Arrowood MJ, Orlandi Jr PA, da Silva AJ, Bier JW, Hanauer SD, Kuster RI, Oltman S, Baldwin MS, Won KY, Nace EM, Eberhard ML, Herwaldt BL. Outbreak of cyclosporiosis associated with basil in Missouri in 1999. Clin Infect Dis 2001; 32: 1010-1017.

76. Ho AY, Lopez AS, Eberhart MG, Levenson R, Finkel BS, da Silva AJ, Roberts JM,
Orlandi PA, Johnson CC, Herwaldt BL. Outbreak of cyclosporiasis associated with imported raspberries, Philadelphia, Pennsylvania, 2000. Emerg Infect Dis 2002; 8: 783-788.

77. Doller PC, Dietrich K, Filipp N, Brockmann S, Dreweck C, Vonthein $R$, Wagner-Wiening $C$, Wiedermann A. Cyclosporiasis outbreak in Germany associated with the consumption of salad. Emerg Infect Dis 2002; 8: 922-994.

78. Ayala-Gaytan JJ, Diaz-Olachea C, Riojas-Montalvo P, Palacios-Martinez C. Cyclosporidiosis: clinical and diagnostic characteristics of an epidemic outbreak. Rev Gastroenterol Mex 2004; 69: 226-229.

79. Hoang LM, Fyfe M, Ong C, Harb J, Champagne S, Dixon B, Isaac-Renton J. Outbreak of cyclosporiasis in British Columbia associated to imported Thai basil. Epidemiol Infect 2005; 133: 23-27.

80. Blans MC, Ridwan BU, Verweij JJ, Rozenberg-Aroka M, Verhoef J. Cyclosporiasis outbreaks, Indonesia. Emerg Infect Dis 2005; 11: 1453-1455.

81. Botero-Garcés J, Montoya-Palacio MN, Barguil JI, Castaño-González A. Brote epidémico por Cyclospora cayetanensis en Medellín, Colombia. Rev Salud Publ (Bogotá) 2006; 8: 258-268.

82. Puente S, Morente A, Garcia-Benayas T, Subirats M, Gascon J, Gonzalez-Lahoz JM. Cyclosporiasis: a point source outbreak acquired in Guatemala. J Travel Med 2006; 13: 334-337.

83. Kozak GK, MacDonald D, Landry L, Farber JM. Foodborne outbreaks in Canada linked to produce: 2001 through 2009. J Food Prot 2013; 76:173-183.

84. Public Health Agency of Canada (PHAC). Annual laboratory surveillance data for enteric pathogens in Canada. Ottawa, Canada. 2006. Available online: http://www.

Vol. 59(1): 67 - 93, 2018 
phac-aspc.gc.ca/index-eng.php. Public Health Notice Update Accessed on March 2017.

85. Centers for Disease Control and Prevention (CDC). Outbreak of cyclosporiasis associated with snow peas Pennsylvania. MMWR Morb Mortal Wkly Rep 2004; 53: 876-878.

86. Torres-Slimming PA, Mundaca CC, Moran M, Quispe J, Colina O, Bacon DJ, Lescano AG, Gilman RH, Blazes DL. Outbreak of cyclosporiasis at a naval base in Lima Peru. Am J Trop Med Hyg 2006; 75: 546-548.

87. Mundaca CC, Torres-Slimming PA, Araujo-Castillo RV, Moran M, Bacon DJ, Ortega Y, Gilman RH, Blazes DL. Use of PCR to improve diagnostic yield in an outbreak of cyclosporiasis in Lima Peru. Trans R Soc Trop Med Hyg 2008; 102: 712717.

88. Hammond R. Cyclospora outbreak in Florida, 2005. Abstract. S15. Food-borne Threats Health Policies Pract Surveill Prev. Outbreak Invest. Int. Coord. Workshop, Washington, DC, 25 to 26 October 2005.

89. Public Health Agency of Canada (PHAC). Annual laboratory surveillance data for enteric pathogens in Canada. Ottawa, Canada. 2007. Available online: http://www. phac-aspc.gc.ca/ Accessed on March 2017.

90. Shah L, MacDougall L, Ellis A, Ong C, Shyng S, LeBlanc L; British Columbia Cyclospora Investigation Team. Challenges of investigating community outbreaks of cyclosporiasis. Emerg Infect Dis 2009; 15:1286-1288.

91. Ozdamar MT, Turkoglu S, Hakko E. Outbreak of cyclosporiasis in Istanbul, Turkey during an extremely dry and warm summer. (Abstract) 18th Congress. Clin Microbiol Infect Dis 2008. Barcelona, Spain. P. 988.
92. Centers for Disease Control and Prevention (CDC). Outbreaks updates for international cruise ships. 2009. Available online: http://www.cdc.gov/nceh/vsp/surv/ Gllist.htm \#2009. Accessed on March 2017.

93. Insulander M, Svenungsson B, Lebbad M, Karlsson L, de Jong B. A foodborne outbreak of Cyclospora infection in Stockholm, Sweden. Foodborne Pathog Dis 2010; 7:1585-1587.

94. Gibbs RA, Nanyonjo R, Pingault NM, Combs BG, Mazzucchelli T, Armstrong P, Tarling G, Dowse GK. An outbreak of Cyclospora infection on a cruise ship. Epidemiol Infect 2013; 141: 508-516.

95. Abanyie F, Harvey RR, Harris JR, Wiegand RE, Gaul L, DesvignesKendrick M, Irvin K, Williams I, Hall RL, Herwaldt B, Gray EB, Qvarnstrom Y, Wise ME, Cantu V, Cantey PT, Bosch S, DA Silva AJ, Fields A, Bishop H, Wellman A, Beal J, Wilson N, Fiore AE, Tauxe R, Lance S, Slutsker L, Parise M; Multistate Cyclosporiasis Outbreak Investigation Team. Multistate outbreaks of Cyclospora cayetanensis infections associated with fresh produce: focus on the Texas investigations. Epidemiol Infect 2013; 143: 3451-3458.

96. Buss BF, Joshi MV, O'Keefe AL, Allensworth CD, Garvey A, Obbink K, Mandernach S, Safranek TJ. Regional investigation of a cyclosporiasis outbreak linked to imported romaine lettuce Nebraska and Iowa, June-August 2013. Epidemiol Infect 2016; 144: 1807-1817.

97. Bednarska M, Bajer A, Welc-Faleciak R, Pawelas A. Cyclospora cayetanensis infection in transplant traveller: a case report of outbreak. Parasit Vectors 2015; 8: 411.

98. Public Health Agency of Canada (PHAC). Public health notice update -outbreak of Cyclospora under investigation. Ottawa, Canada. 2015. Available online: http://www. 
phac-aspc.gc.ca/index-eng.php Accessed on April 17.

99. Nichols GL, Freedman J, Pollock KG, Rumble C, Chalmers RM, Chiodini P, Hawkins G, Alexander CL, Godbole G, Williams C, Kirkbride HA, Hamel M, Hawker JI. Cyclospora infection linked to travel to Mexico, June to September 2015. Euro Surveill 2015 October; 20(43). Available online: http://www. eurosurveillance.org

100. Centers for Disease Control and Prevention (CDC). Cyclosporiasis outbreak investigations-United States, 2014. Available online: http://www.cdc.gov/ parasites,cyclosporiasis/outbreaks/2014/ Accessed on April 17.

101. Centers for Disease Control and Prevention (CDC). Cyclosporiasis outbreak investigations-United States, 2015. Available online: http://www.cdc.gov/ parasites/cyclosporiasis/outbreaks/2015/ Accessed on April 17.

102. Soave R, Dubey JP, Ramos LJ, Tummings M. A new intestinal pathogen? Clin Res 1986; 34: 533 A.

103. Hall RL, Jones JL, Herwaldt BL. Surveillance for laboratory-confirmed sporadic cases of cyclosporiasis-United States, 1997-2008. MMWR Surveill Summ 2011; 60:1-11.

104. Thomas MK, Murray R, Flockhart L, Pintar K, Pollari F, Fazil A, Nesbitt A, Marshall B. Estimates of the burden of foodborne illness in Canada for 30 specified pathogens and unspecified agents, Circa 2006. Foodborne Pathog Dis 2013; 10: 639648.

105. Chambers J, Somerfeldt S, Mackey L, Nichols S, Ball R, Roberts D, Dufford N, Reddick A, Gibson J. Outbreaks of Cyclospora cayetanensis infection-United States. MMWR Morb Mortal Wkly Rep
1996; 45: 549-551.

106. Anonymous. Update: outbreaks of cyclosporiasis - United States and Canada. Can Comm Dis Rep 1997; 2: 143-144.

107. Shields JM, Olson BH. Cyclospora cayetanensis: a review of an emerging parasitic coccidian. Int J Parasitol 2003; 33: 371-391.

108. Karanis $P$, Kourenti $C$, Smith $H$. Waterborne transmission of protozoan parasites: a worldwide review of outbreaks and lessons learnt. J Water Health 2007; 5:138 .

109. Baldursson S, Karanis P. Waterborne transmission of protozoan parasites: Review of worldwide outbreaks- An update 20042010. Water Res 2011; 45: 6603- 6614.

110. Wurtz R. Cyclospora: a newly identified intestinal pathogen of humans. Clin Infect Dis 1994; 18: 620-623.

111. Hale D, Aldeen W, Carroll K. Diarrhea associated with Cyanobacteria- like bodies in an immunocompetent host. An unusual epidemiological source. JAMA 1994; 271: 144-145.

112. Ooi WW, Zimmerman SK, Needham CA. Cyclospora species as a gastrointestinal pathogen in immunocompetent hosts. J Clin Microbiol 1995; 33: 1267-1269.

113. Clarke SC, McIntyre M. The incidence of Cyclospora cayetanensis in stool samples submitted to a district general hospital. Epidemiol Infect 1996; 117: 189-193.

114. Bouree P, Lancon A, Bonnot G. Une parasitose emergente: la cyclosporose. Revue a propos de five observations. Antibiotiques 2006; 8: 73-78.

115. Ribes JA, Seabolt JP, Overman SB. Point prevalence of Cryptosporidium, Cyclospora, and Isospora infections in patients being evaluated for diarrhea. Am J Clin Pathol 2004; 122: 28-32.

116. Hall RL, Jones JL, Hurd S, Smith

Vol. 59(1): 67 - 93, 2018 
G, Mahon BE, Herwaldt BL. Populationbased active surveillance for Cyclospora infection-United States, Foodborne Diseases Active Surveillance Network (FoodNet), 1997-2009. Clin Infect Dis 2012; 54: S411417.

117. Herwaldt BL. The ongoing saga of U.S. outbreaks of cyclosporiasis associated with imported fresh produce: what Cyclospora cayetanensis has taught us and what we have yet to learn. In Institute of Medicine (ed.). Addressing foodborne threats to health: policies, practices, and global coordination. National Academics Press, Washington, DC. 2006. P. 85-115, 133-140. 2006.

118. Hoge CW, Echeverria $P$, Rajah $R$, Jacobs J, Malthouse S, Chapman E, Jimenez LM, Shlim DR. Prevalence of Cyclospora species and other enteric pathogens among children less than 5 years of age in Nepal. J Clin Microbiol 1995; 33: 3058-3060.

119. Sherchand JB, Cross JH. Emerging pathogen Cyclospora cayetanensis infection in Nepal. Southeast Asian J Trop Med Public Health 2001; 32: 143-150.

120. Zhou Y, Lv B, Wang Q, Wang R, Jian F, Zhang L, Ning C, Fu K, Wang Y, Qi M, Yao H, Zhao J, Zhang X, Sun Y, Shi K, Arrowood MJ, Xiao L. Prevalence and molecular characterization of Cyclospora cayetanensis, Henan, China. Emerg Infect Dis 2011; 17: 1887-1890.

121. Bern C, Ortega YR, Checkley W, Roberts JM, Lescano AG, Cabrera L, Verastegui M, Black RE, Sterling C, Gilman RH. Epidemiologic differences between cyclosporiasis and cryptosporidiosis in Peruvian children. Emerg Infect Dis 2002; 8: 581-585.

122. Turgay N, Yolasigmaz A, Erdogan DD, Zeyrek FY, Uner A. 2007. Incidence of cyclosporiasis in patients with gastrointestinal symptoms in western Turkey. Med Sci Monit 2007; 13: 34-39.

123. Eberhard ML, Nace EK, Freeman AR, Streit TG, Da Silva AJ, Lammie PJ. Cyclospora cayetanensis infections in Haiti: a common occurrence in the absence of watery diarrhea. Am J Trop Med Hyg 1999; 60: 584-586.

124. Ortega YR, Nagle R, Gilman RH, Watanabe J, Miyagui J, Quispe H, Kanagusuku P, Roxas C, Sterling CR. Pathologic and clinical findings in patients with cyclosporiasis and a description of intracellular parasite life-cycle stages. J Infect Dis 1997; 176: 1584-1589.

125. Zerpa $R$, Uchima $N$, Huicho $L$. Cyclospora cayetanensis associated with watery diarrhoea in Peruvian patients. J Trop Med Hyg 1995; 98: 325-329.

126. Mansfield LS, Gajadhar AA. Cyclospora cayetanensis, a food- and waterborne coccidian parasite. Vet Parasitol 2004; 126: 73-90.

127. Ortega YR, Sterling CR, Gilman RH. Cyclospora cayetanensis. Adv Parasitol 1998; 40: 339-418.

128. Sherchand JB, Cross JH, Jimba M, Sherchand S, Shrestha MP. Study of Cyclospora cayetanensis in health care facilities, sewage water and green leafy vegetables in Nepal. Southeast Asian J Trop Med Public Health 1999; 30: 58-63.

129. Garcia-Lopez HL, Rodriguez-Tovar LE, Medina-de la Garza CE. Identification of Cyclospora in poultry. Emerg Infect Dis 1996; 2: 356-357.

130. Yai LE, Bauab AR, Hirschfeld MP, de Oliveira ML, Damaceno JT. The first two cases of Cyclospora in dogs, Sao Paulo, Brazil. Rev Inst Med Trop S Paulo 1997; 39: 177-179.

131. Perez Cordon G, Prados AH, Romero D, Moreno MS, Pontes A, Osuna A, 
Rosales MJ. Intestinal and haematic parasitism in the birds of the Almuñecar (Granada, Spain) ornithological garden. Vet Parasitol 2009; 165: 361-366.

132. Perez Cordon G, Hitos Prados A, Romero D, Moreno M, Pontes A, Osuna A, Rosales MJ. Intestinal parasitism in the animals of the zoological garden "Peña Escrita" (Almuñecar, Spain). Vet Parasitol 2008; 156: 302-309.

133. Chu DM, Sherchand JB, Cross JH, Orlandi PA. Detection of Cyclospora cayetanensis in animal fecal isolates from Nepal using an FTA filter-base polymerase chain reaction method. Am J Trop Med Hyg 2004; 71: 373-379.

134. Li N, Ye J, Arrowood MJ, Ma J, Wang L, Xu H, Feng Y, Xiao L. Identification and morphologic and molecular characterization of Cyclospora macacae n. sp. from rhesus monkeys in China. Parasitol Res 2015; 114: 1811-1816.

135. Eberhard ML, Nace EK, Freeman AR. Survey for Cyclospora cayetanensis in domestic animals in an endemic area in Haiti. J Parasitol 1999; 85: 562-563.

136. Carollo MC, Amato Neto V, Braz LM, Dowoong K. Pesquisa de oocistos de Cyclospora sp., em fezes de caes da Grande Sao Paulo, Estado de Sao Paulo, Brasil. Rev Soc Bras Med Trop 2001; 34: 597-598.

137. Ortega YR, Roxas CR, Gilman RH, Miller NJ, Cabrera L, Taquiri C, Sterling CR. Isolation of Cryptosporidium parvum and Cyclospora cayetanensis from vegetables collected in markets of an endemic region in Peru. Am J Trop Med Hyg 1997; 57: 683-686.

138. Eberhard ML, Ortega YR, Hanes DE, Nace EK, Do RQ, Robl MG, Won KY,Eberhard ML, Ortega YR, Hanes DE, Nace EK, Do RQ, Robl MG, Won KY,Gavidia C, Sass NL, Mansfield
K, Gozalo A, Griffiths J, Gilman R, SterlingCR, Arrowood MJ. Attempts to establish experimental Cyclospora cayetanensis infection in laboratory animals. J Parasitol 2000; 86: 577-582.

139. Sadaka HA, Zoheir MA. 2001. Experimental studies on cyclosporiosis. J Egypt Soc Parasitol 2001; 31: 65-77.

140. Negm AY. Human pathogenic protozoa in bivalves collected from local markets in Alexandria. J Egypt Soc Parasitol 2003; 33: 991-998.

141. Aksoy U, Marangi M, Papini R, Ozkoc S, Bayram Delibas S, Giangaspero A. Detection of Toxoplasma gondii and Cyclospora cayetanensis in Mytilus galloprovincialis from Izmir Province coast (Turkey) by real time PCR/high resolution melting analysis (HRM). Food Microbiol 2014; 44: 128-135.

142. El-Karamany EM, Zaher TI, elBahnasawy MM. Role of water in the transmission of cyclosporiasis in Sharkia Governorate, Egypt. J Egypt Soc Parasitol 2005; 35: 953-962.

143. Dixon B, Parrington L, CookA, Pollari F, Farber J. Detection of Cyclospora, Cryptosporidium, and Giardia in readyto-eat packaged leafy greens in Ontario, Canada. J Food Prot 2013; 76: 307-313.

144. Lopez AS, Dodson DR, Arrowood MJ, Orlandi Jr PA, da Silva AJ, Bier JW, Hanauer SD, Kuster RI, Oltman S, Baldwin MS, Won KY, Nace EM, Eberhard ML, Herwaldt BL. Outbreak of cyclosporiosis associated with basil in Missouri in 1999. Clin Infect Dis 2001; 32: 1010-1017.

145. Kitajima M, Haramoto E, Iker BC, Gerba CP. Occurrence of Cryptosporidium, Giardia, and Cyclospora in influent and effluent water at wastewater treatment plants in Arizona. Sci Total Environ 2014;

Vol. 59(1): 67 - 93, 2018 
484:129-36.

146. Dowd SE, John D, Eliopolus J, Gerba CP, Naranjo J, Klein R, Lopez B, de Mejia M, Mendoza CE, Pepper IL. Confirmed detection of Cyclospora cayetanensis, Encephalitozoon intestinalis and Cryptosporidium parvum in water used for drinking. J Water Health 2003; 1: 117123.

147. Calvo M, Carazo M, Arias ML, Chaves C, Monges R, Chinchilla M. Prevalencia de Cyclospora sp., Cryptosporidium sp., microsporidios y determinación de coliformes fecales en frutas $y$ vegetales frescos de consumo crudo en Costa Rica. Arch Latinoam Nutr 2004; 54: 428-432.

148. Devera $R$, Blanco $Y$, González $H$, García L. Parásitos intestinales en lechugas comercializadas en mercados populares y supermercados de Ciudad Bolívar, Estado Bolívar, Venezuela. Rev Soc Venezol Microbiol 2006; 26:100-107.

149. Sturbaum GD, Ortega YR, Gilman RH, Sterling CR, Cabrera L, Klein DA. Detection of Cyclospora cayetanensis in wastewater. Appl Environ Microbiol 1998; 64: 2284-2286.

150. Galván AL, Magnet A, Izquierdo F, Fenoy S, Rueda C, Fernández Vadillo C, Henriques-Gil N, del Aguila C. Molecular characterization of human-pathogenic microsporidia and Cyclospora cayetanensis isolated from various water sources in Spain: a year-long longitudinal study. Appl Environ Microbiol 2013; 79: 449-459.

151. Giangaspero A, Marangi M, Arace E. Cyclospora cayetanensis travels in tap water on Italian trains. J Water Health 2015; 13: 210-216.

152. Giangaspero A, Marangi M, Koehler AV, Papini R, Normanno G, Lacasella V, Lonigro A, Gasser RB. Molecular detection of Cyclospora in water, soil, vegetables and humans in southern Italy signals a need for improved monitoring by health authorities. Int J Food Microbiol 2015; 211:95-100.

153. MiegevilleM,KoubiV,DanLC,Barbier JP, Cam PD. Cyclospora cayetanensis presence in aquatic surroundings in Hanoi (Vietnam). Environmental study (well water, lakes and rivers). Bull Soc Path Exot 2003; 96: 149-152.

154. Tram NT, Hoang LM, Cam PD, Chung PT, Fyfe MW, Isaac-Renton JL, Ong CS. Cyclospora spp. in herbs and water samples collected from markets and farms in Hanoi, Vietnam. Trop Med Int Health 2008; 13: 1415-1420.

155. Vuong TA, Nguyen TT, Klank LT, Phung DC, Dalsgaard A. Faecal and protozoan parasite contamination of water spinach (Ipomoea aquatica) cultivated in urban wastewater in Phnom Penh, Cambodia. Trop Med Int Health 2007; 12: 73-81.

156. Sim S, Won J, Kim JW, Kim K, Park WY, Yu JR. Simultaneous molecular detection of Cryptosporidium and Cyclospora from raw vegetables in Korea. Korean J Parasitol 2017; 55: 137-142.

157. Ben-Ayed L, Yang W, Widmer G, Cama V, Ortega Y, Xiao L. Survey and genetic characterization of wastewater in Tunisia for Cryptosporidium spp., Giardia duodenalis, Enterocytozoon bieneusi, Cyclospora cayetanensis and Eimeria spp. J Water Health 2012; 103: 431-444.

158. Salman YJ, Kadir MA, Abdul-Allah TJ. Prevalence of Cyclospora cayetanensis and other intestinal parasites in soil samples collected from Kirkuk Province. Int J Curr Res Aca Rev 2015; 3: 239-250.

159. Abou el Naga LF. Studies on a newly emerging protozoal pathogen: Cyclospora cayetanensis. J Egypt Soc Parasitol 1999; 29: 575-586. 
160. Elshazly AM, Elsheikha HM, Soltan DM, Mohammad KA, Morsy TA. Protozoal pollution of surface water sources in Dakahlia Governorate, Egypt. J Egypt Soc Parasitol 2007; 37, 51-64.

161. El Said D. Detection of parasites in commonly consumed raw vegetables. Alexandria J Med 2012; 48: 345-352.

162. Kwakye-Nuako G, Borketey P, Mensah-Attipoe I, Asmah R, Ayeh-Kumi P. Sachet drinking water in Accra: the potential threats of transmission of enteric pathogenic protozoan organisms. Ghana Med J 2007; 41: 62-67.

163. Duedu KO, Yarnie EA, TettehQuarcoo PB, Attah SK, Donkor ES, Ayeh-Kumi PF. A comparative survey of the prevalence of human parasites found in fresh vegetables sold in supermarkets and open-aired markets in Accra Ghana. BMC Res Notes 2014 Nov; 7: 836. Available online: https://www.ncbi.nlm.nih.gov

164. Smith HV, Paton CA, Girdwood RW, Mtambo MM. Cyclospora in nonhuman primates in Gombe, Tanzania. Vet Rec 1996; 138: 528.

165. Dixon, BR, Bussey JM, Parrington LJ, Parenteau M. Detection of Cyclospora cayetanensis oocysts in human fecal specimens by flow cytometry. J Clin Microbiol 2005; 43: 2375-2379.

166. Chacín-Bonilla L. El problema de las parasitosis intestinales en Venezuela Invest Clín 1990; 31: 1-2.

167. Chacín-Bonilla L, Dikdan Y. Prevalencia de Entamoeba histolytica y otros parásitos intestinales en una comunidad suburbana de Maracaibo. Invest Clín 1981; 22: 185-203.

168. Chacín-Bonilla L, Dikdan Y, Guanipa N, Villalobos R. Prevalencia de Entamoeba histolytica y otros parásitos intestinales en un barrio del Municipio Mara, Estado Zulia,
Venezuela. Invest Clín 1990; 31: 3-15.

169. Guo Y, Roellig DM, Li N, Tang K, Frace M, Ortega Y, Arrowood MJ, Feng Y, Qvarnstrom Y, Wang L, Moss DM, Zhang L, Xiao L. Multilocus sequence typing tool for Cyclospora cayetanensis. Emerg Infect Dis 2016; 22: 1464- 1467.

170. Food and Drug Administration (FDA). U.S.-Mexico Partnership enhances the safety of fresh cilantro (Coriandrum sativum). 2015. Available online: www.fda. gov/Food/FoodborneillnessContaminants/ BuyStoreServeSafeFood/ucm455941.htm. Accessed on April 2017.

171. Gerba CP, Pepper IL, Whitehead LF. 2002. A risk assessment of emerging pathogens of concern in the land application of bio-solids. Water Sci Technol 2002; 46: 225-230.

172. Ortega YR, Liao J. Microwave inactivation of Cyclospora cayetanensis sporulation and viability of Cryptosporidium parvum. J Food Prot 2006; 69: 1957-1960.

173. Sathyanarayanan L, Ortega Y. 2006. Effects of temperature and different food matrices on Cyclospora cayetanensis oocyst sporulation. J Parasitol 2006; 92:218-222.

174. Lee MB, Lee EH. Coccidial contamination of raspberries: mock contamination with Eimeria acervulina as a model for decontamination treatment studies. J Food Prot 2001; 64:1854-1857.

175. Kniel KE, Shearer AE, Cascarino JL, Wilkins GC, Jenkins MC. High hydrostatic pressure and UV light treatment of produce contaminated with Eimeria acervulina as a Cyclospora cayetanensis surrogate. J Food Prot 2007; 70: 2837-2842. 
